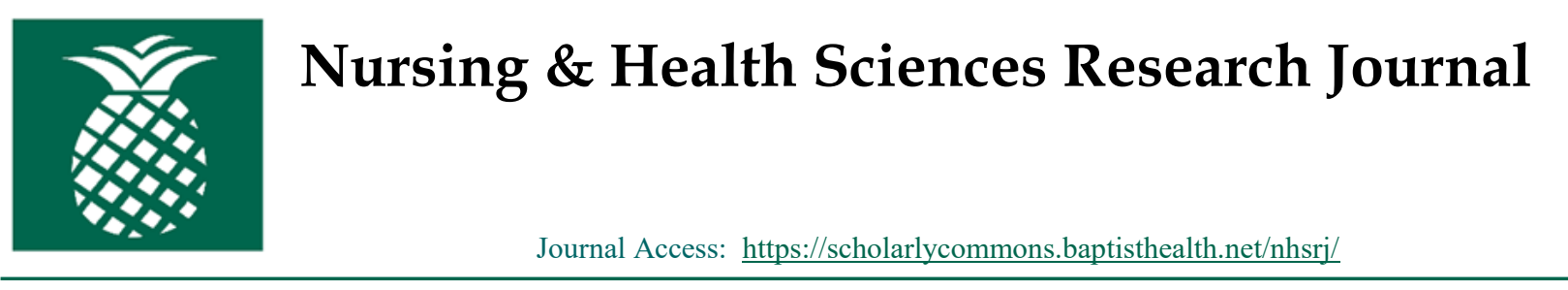

\title{
Evaluation of the Clinical Competency Advancement Program
}

Nada Wakim, PhD, RN, NE-BC; Nohemi Sadule-Rios, PhD, APRN; Suzanne Balbosa-Saunders, MSN, MSH, RN, NEA-BC; Eve Butler, PhD, RN, Becky Montesino-King, DNP, RN, NEA-BC, CENP

\section{ABSTRACT}

Introduction: A major challenge facing nursing administrators and recruiters is the recruitment and retention of bedside nurses. Clinical career ladder programs are used as recruitment and retention tools by many hospitals. The Clinical Competency Advancement Program (CCAP) is a clinical career ladder program developed by a health system in South Florida to help retain clinical nurses at the bedside. The purpose of this study was to assess nurses' attitudes related to the CCAP, by both participants and non-participants, to determine the perceived barriers and benefits of the program.

Methods: This study used a descriptive comparative design. A convenience sample of 979 register ed nurses from seven Magnet巴 certified hospitals within a healthcare system in South Florida participated in the study. A modified version of The Professional Nurse Contribution Ladder Instrument was used for data collection.

Results: The results showed that CCAP participants perceived monetary reward as the main reason for participation and that the CCAP application process is more reasonable and less overwhelming than the former career ladder program, Professional Nursing Advancement Program (PNAP). Furthermore, participants indicated they were happy and satisfied with the benefits and rewards of the CCAP program. Nurses, who participated in CCAP, were more satisfied and more likely to stay in their jobs. The most difficult criteria of CCAP to fulfill included years of service, floating, assuming the charge nurse role, and being a member of entity project or committee. The results were used to modify the current version of CCAP.

Discussion: To increase participation of bedside nurses in clinical career ladders it is imperative that nurse leaders often review these career ladders to make modifications that are impactful on nurse retention and nurse job satisfaction by integrating these satisfiers.

Keywords: Career ladder, Nurse satisfaction, Recruitment, Retention, Professional advancement

\section{INTRODUCTION}

It is estimated that in the United States, the nursing shortage will intensify during the next few decades. The shortage is projected to grow to 260,000 registered nurses by 2025 (Bureau of Labor Statistics, 2013). This nursing shortage would constitute a shortage twice as large as any experienced in this country since the mid-1960s (American Association of Colleges of Nursing, 2014). To mitigate the effects of the nursing shortage, healthcare organizations implement programs, such as Professional Nurse Advancement Programs (also known as Clinical Career Ladder Programs) that focus on recruitment and retention of their nurses.

Professional Nurse Advancement Programs or Clinical Career Ladder Programs, are clinical programs developed in the early 1970s in response to a national nursing shortage. These programs are defined as structures that facilitate professional growth in the clinical setting and are coupled with pay variation based upon different levels of clinical and professional nursing practice (Pierson, Liggett, \& Moore 2010). The programs do not completely eliminate the nursing shortage but they can alleviate it. Professional Nurse Advancement Programs or Clinical Career Ladder Programs can be applied as competitive marketing strategies in times of overwhelming nursing shortages and increasingly consumer-driven healthcare (Watts, 2010). These programs highlight that healthcare organizations are strongly dedicated to providing a positive work environment with the highest quality and safest care, offered by professionally developed clinical experts.

Many benefits of participating in Professional Nurse Advancement Programs or Clinical Career Ladder Programs have been identified. Numerous studies have positively linked these programs to increased job 
satisfaction, retention, recruitment, and patient satisfaction (Ke \& Hung, 2017; Watts, 2010). Ke and Hung (2017) found a significant difference in nurses' intent to stay based on their level on the clinical ladder. Nurses at the highest level of advancement were more willing to stay as compared to nurses who did not advance. Clinical ladder programs have been shown to enhance professional development, improve staff relations, reward competency, and heighten nurses' motivation in their work (Watts, 2010). Benefits include gaining recognition with peers and administration, personal satisfaction, financial incentives, and personal growth (Tetuan, Browder, Ohm, \& Mosier, 2013; Watts, 2010).

A vital benefit of these programs for organizations is decreased turnover and increased staff retention resulting in cost savings (Zehler, Covert, Seiler, Lewis, Perazzo \& Beery, 2015). However, in contrast, one study by Tetuan, Browder, Ohm, and Mosier (2013) reported no significant statistical difference on job satisfaction and likelihood to stay between nurses who participated in a clinical ladder program and those who did not. Notwithstanding the numerous benefits of participating in these programs, there is still a large number of nurses who choose not to participate. Noted barriers include the belief that the ladder documents accomplishments but does not determine a nurse's proficiency or competency (Knoche \& Meucci, 2015). Results of a study indicated that nurse anesthetists reported the lack of time during working hours to pursue professional development activities and lack of manager engagement as barriers (Averlid, 2017). Additionally, these programs are not always available in outpatient settings such as clinics (Tetuan, Browder, Ohm, Mosier, 2013). In another study, nurses expressed that it took too much time and energy and may interfere with personal responsibilities (Tetuan, Browder, Ohm, \& Mosier, 2013). Zehler et al. (2015) reported that the biggest barrier for nurses was committee attendance and the time it took away from patient care.

While clinical ladder programs are designed to benefit the employment and preservation of competent nurses, they can also provide the tools to promote professional and leadership skills development and provide strategies to improve the decision-making skills of nurses at the bedside (Warman, Williams, Herrero, Fazeli, \& White-Williams, 2016). Before these programs were introduced, some hospitals had poor levels of satisfaction regarding nurses and their careers, lower retention, and lower recruitments rates (Tetuan, Browder, Ohm, Mosier, 2013). Furthermore, the lack of acknowledgment for performance, dedication, and hard work are some of the principal threats to nursing satisfaction. The exploration of professional advancement programs in comparison to costs, financial influence, and benefits are essential to rationalize the salary increases for these programs.

The Professional Nurse Advancement Program (PNAP), a career nurse advancement program at a
South Florida healthcare system, was developed in 2007 to recognize nurses who choose to remain at the bedside and concentrate on their clinical expertise. It was also viewed as a retention and recruitment tool. Over nine years, minor revisions were made to the program, but not to its inherent purpose or structure. During the same time-period, nurses working for the system showed decreasing interest in participating in PNAP and found the criteria hard to meet. The difficulty was due in part because all the various components of the program had to be fulfilled (such as a research paper, specialty certification, enrollment or achievement of a Bachelor's of Science in Nursing degree). In November 2016, a council consisting of educators, leaders, and bedside staff met to review relevant literature related to clinical ladders because of dissatisfaction expressed by nursing staff throughout the system at town hall meetings, councils, and staff meetings. After a detailed review by the council, recommendations for program modifications were made to leadership. The leadership decided to revamp PNAP and a new nurse career program based on an optional point system emerged and was called the Competency and Clinical Advancement Program (CCAP), which was implemented in March 2017.

Given the benefits of the Professional Nurse Advancement Programs or Clinical Nurse Career Ladder Programs towards job satisfaction and nurse retention and having recognized the barriers to participation in these programs, research studies that focus on examining how these programs can result in higher retention rates and increased nurse satisfaction will benefit organizations. Nurse leaders at a South Florida health care system have recognized the need to evaluate their newly established clinical nurse career advancement program to help retain their bedside nurses, decrease turnover, and increase job satisfaction. The purpose of this study was to assess nurse's attitudes of the CCAP, a Career Nurse Advancement Program at a South Florida healthcare system, by both participants and nonparticipants to determine the perceived barriers and benefits.

\section{METHODS}

\section{Design, Sample, and Setting}

This study used a descriptive comparative research design. A convenience sample of 979 registered nurses from seven different Magnet ${ }^{\circledR}$ certified hospitals within the same health system in South Florida participated in the study. The inclusion criteria included registered nurses working at the bedside full time or part-time. Registered nurses working per diem and not working at the bedside were excluded from participation.

\section{Data Collection}

A modified version of The Professional Nurse Contribution Ladder Instrument (PNCLI) was used for 
data collection (Tetuan, T., Browder, B., Ohm, R., \& Mosier, M., 2013). The PNCLI, found during literature review, has been used to evaluate clinical advancement programs and has been shown to have content validity and high reliability, with a reported internal consistency, Cronbach's $\alpha=.961$ for the attitude scale and Cronbach's $\alpha=.899$ for the job satisfaction scale (Tetuan et al., 2013). Permission was obtained from the original instrument author to modify the survey instrument for use in this study. The instrument was modified to meet the need for this research study. The modified survey instrument consisted of a 9-item modified demographic measure, a 9-item modified Likert scale attitude measure, an added 3-item attitude measure to compare CCAP to PNAP, a 9-item Likert scale job satisfaction measure including a 1-item "considered leaving" measure, and open-ended questions for nurses to enter comments about the CCAP. The last section of the survey included a 9-item benefits and barriers measure.

\section{Protection of Human Subjects}

The study was approved by the Institutional Review Board's (IRB) review process. This included an initial assessment by the system peer-facilitated review process and final review and approval by IRB. Permission was obtained from the Chief Nursing Officers (CNO) of each entity to use staff email addresses. An email was sent to each nurse's work email address explaining the study its purpose, the right to withdraw or participate, compensation, risks, benefits, confidentiality, and a link to the survey. Participants had the opportunity to take the online survey voluntarily. Completion of the survey indicated consent to participate in the study. The data were collected and managed using REDCap.

\section{Data Analysis}

Data were analyzed using SPSS Statistics, version 24. Descriptive statistics were used to determine frequencies relative to the demographic and Likert-scale questions. The non-parametric Mann-Whitney's U test was used to determine the statistical difference between participation and non-participation in the CCAP in mean attitudes, job satisfaction, and retention scores. The most reoccurring responses to the open-ended questions were selected as exemplars.

\section{RESULTS}

\section{Demographics}

A total of $N=979$ nurses participated in the study. Many of the participants were RNs who have worked between $0-5$ years $(18.9 \%), 6$ to 10 years $(15.4 \%)$, or $>20$ years $(20.9 \%)$. The majority of the participants worked at the institutions from $0-15$ years $(58.9 \%)$ and had a Bachelor's Degree (50.4\%). Most of the participants worked on a Medical/Surgical floor, Emergency Department, Critical Care, or Surgery (58.4\%). Most participants worked full time $(65.3 \%)$ during day shift 7a-7p (49.1\%). Also, most nurses were between 31 and 60 years old $(54 \%)$. Finally, many of the nurses participated in CCAP (39.2\%) and achieved the Advanced Level $(22.6 \%)$.

\section{CCAP Participants Perceived Benefits Toward Par- ticipation in CCAP}

The majority of CCAP participants selected four reasons for participation, monetary reward $(n=335$, $88 \%$ ), professional recognition $(n=266,70 \%)$, professional reward $(n=255,67 \%)$, and professional growth $(n=274,72 \%)$. One of the participants shared that "It's a great motivation for me financially and be recognized as senior in this field and looking forward to work knowing that we are compensated and makes us proud of what we do as a nurse." Another respondent stated that "Salary raise increase changed my mind from leaving" and "I am very happy with CCAP; it has given me the opportunity for professional development, and positive financial rewards." Additionally, most of the participants $(n=295,78 \%)$ indicated that the application process was reasonable and that they were satisfied with rewards and recognition $(n=258$, $68 \%)$. The majority of the participants $(n=242,65 \%)$ indicated that their work area had benefited by their participation in the ladder and agreed that they can meet the top level of the ladder by stretching a little outside of their daily work responsibilities $(n=198$, $53 \%$ ). One of the participants stated, "Thank you for making the ladder easier and simpler to attain, advancement is fair and just..." Finally, most CCAP participants indicated that they would continue to participate in CCAP in the future $(n=310,83 \%)$.

\section{CCAP Participants Perceived Barriers toward Par- ticipation in PNAP}

The majority of CCAP participants indicated that they did not participate in the PNAP program because the research/evidence-based paperwork was overwhelming $(n=122,54 \%)$. Similarly, most participants $(n=152,71 \%)$ selected that the PNAP criteria that were the hardest to meet were research projects, appraisal of evidence-based practice, and patient safety projects. One of the respondents went on to say "I am glad that the CCAP process became less dependent on the research project component." The PNAP application process was considered time-consuming by most of the participants $(n=128,62 \%)$ and the paperwork was overwhelming $(n=142,69 \%)$. One of the participants stated "The CCAP is perfect, it allows me to benefit in going up the ladder... I was already doing it all but I didn't do PNAP because it was timeconsuming." Another participant mentioned that "PNAP requires too much time for extracurricular activities." 
Non-CCAP Participants Perceived Barriers Toward Participation in CCAP

The majority of those who did not participate in CCAP indicated that they did not qualify $(n=248$, $77 \%$ ) and that they are highly likely to participate in CCAP in the future $(n=167,49 \%)$. One of the respondents stated that "I did not apply for CCAP at this time due to being ineligible."

\section{Comparison of CCAP Participants and Non Parti- cipants}

\section{Job satisfaction and likelihood to stay.}

The non-parametric Mann-Whitney's U test was used to determine if differences existed in job satisfaction between those who participated in CCAP and those who did not (Table 1). We found a significant effect of Group (The mean ranks of CCAP Participants and Non-Participants were 346.21 and 271.27, respectively; $U=36639.500, Z=-5.886, P<.001, r=0.235$ ). Those who participated in CCAP indicated they were more satisfied with their jobs than those who did not participate. We also compared CCAP participants and non-participants on their likelihood to stay in their jobs. The mean ranks of CCAP Participants and NonParticipants were 349.59 and 259.82, respectively; $U$ $=33485.500, Z=-7.281, P<.001, r=0.292$ (Table 3). Those who participated in CCAP indicated they were

Table 1

\begin{tabular}{|c|c|c|c|c|c|c|}
\hline Groups & $N$ & $\begin{array}{l}\text { Mean } \\
\text { Rank }\end{array}$ & $U$ & $Z$ & Pvalue & $r$ \\
\hline CCAP & 346 & 346.21 & 36639.500 & -5.886 & $.000^{*}$ & 0.235 \\
\hline $\begin{array}{l}\text { Non- } \\
\text { CCAP }\end{array}$ & 279 & 271.27 & & & & \\
\hline
\end{tabular}

more likely to stay in their jobs than those who did not participate. One participant indicated "This program was a great idea for improvement and employee satisfaction. Thank you to those who did this program and approved it", another commented "very good place to work", and "I love the program, thank you for always looking out for your employees' satisfaction. I am proud to be employed by..."

\section{General attitudes toward CCAP.}

Cross-tabulation and Chi-square tests (Cross-tabs $\& X^{2}$ ) were used to evaluate the difference in the responses of the General Attitudes toward the Ladder survey items (Table 2). We compared responses from those who participated in CCAP with those who did not participate in CCAP. The results were not statistically significant on most survey items. Regarding the item Hospitals use of CCAP demonstrates support of the direct care nurse, $8 \%$ of CCAP participants agreed compared to $5 \%$ of non-CCAP participants. This dif- ference was significant $\left(X^{2}=4.405, d f=1, P=.036\right)$. This finding indicates that more CCAP participants believe that the use of the ladder demonstrates support of the direct care nurse. One participant stated, "the process is fair and considered the many achievements of the nurses."

Respondents were also asked to indicate which of the CCAP criteria was the hardest to meet. Significant differences were found on only four of the twelve survey items in this section: Years of Service was chosen by $16 \%$ of CCAP participants and $10 \%$ of nonparticipants. This difference was significant ( $X 2$ $=7.069, d f=1, P=.008$ ). Additionally, Floating was selected by $29 \%$ of CCAP participants and $17 \%$ of non -participants. This difference was significant $\left(X^{2}=\right.$ $24.001, d f=1, P<.001)$. Forty-seven percent of CCAP participants chose Assuming the Charge Nurse Role while only $17 \%$ of non-participants made that choice. This difference was significant $\left(X^{2}=12.563, d f=1\right.$, $P<.001)$. Finally, Member of Entity Project or Committee was selected by $8 \%$ of CCAP participants versus $4 \%$ of non-CCAP participants. This difference was significant $\left(X^{2}=8.691, d f=1, P=.003\right)$ (Table 4). These findings indicate that more CCAP participants considered years of service, floating, assuming the charge nurse role, and member of entity project or committee, the hardest CCAP criteria to meet versus non-CCAP participants. One participant indicated

Table 2

\begin{tabular}{|c|c|c|c|c|c|c|}
\hline Groups & $N$ & $\begin{array}{l}\text { Mean } \\
\text { Rank }\end{array}$ & $U$ & $Z$ & Pvalue & $r$ \\
\hline CCAP & 342 & 349.59 & 33485.000 & -7.281 & $.000^{*}$ & 0.292 \\
\hline $\begin{array}{l}\text { Non- } \\
\text { CCAP }\end{array}$ & 276 & 259.82 & & & & \\
\hline
\end{tabular}

"requiring three years in a current position to qualify for advancement should be reconsidered." Another stated "Resource points - 20 shifts in one year is almost impossible to achieve," and another participant commented, "Seeing that I work night shift, I would like more opportunities to participate in hospital-based committees." Results are presented in Table 3.

\section{DISCUSSION}

A total of 979 nurses participated in this study. Many participants had worked for the healthcare system from 0-15 years or more than 20 years and had a BSN degree. Most worked in Medical Surgical (MS), Emergency Department (ED), Critical Care (CC), or Surgery departments full time during day shift; the majority were aged between $30-60$ years, had participated in CCAP, and achieved the advanced level.

\section{Perceived Benefits Toward Participation in CCAP}


Table 3

General Attitudes toward the Ladder

\begin{tabular}{|c|c|c|c|c|}
\hline Category & $\begin{array}{c}\text { CCAP } \\
\text { Participants } \\
N(\%)\end{array}$ & $\begin{array}{c}\text { Non-CCAP } \\
\text { Participants } \\
N(\%)\end{array}$ & $X^{2}$ & Pvalue \\
\hline \multicolumn{5}{|l|}{ Use of CCAP Demonstrates } \\
\hline Support of the direct care nurse & $60(8 \%)$ & $36(5 \%)$ & 4.405 & .036 \\
\hline \multicolumn{5}{|l|}{ The CCAP Criteria Hardest to Meet } \\
\hline Years of Service & $115(16 \%)$ & $74(10 \%)$ & 7.069 & .008 \\
\hline Floating & $210(29 \%)$ & $127(17 \%)$ & 24.001 & .000 \\
\hline Assuming the Charge Nurse Role & $347(47 \%)$ & $282(39 \%)$ & 12.563 & .000 \\
\hline Member of Entity Project or Committee & $58(8 \%)$ & $28(4 \%)$ & 8.691 & .003 \\
\hline
\end{tabular}

Clinical ladders are used as recruitment and retention tools that provide a structure for bedside care nurses to advance and obtain professional recognition (Korman \& Eliades, 2010). It is important to identify and address the areas of dissatisfaction to retain experienced nurses at the bedside. This is of great importance due to the increased complexity and high acuity of patients nowadays (Riley \& Rolband, 2009). It is also important for healthcare facilities to keep their clinical ladders current. Therefore revisions are necessary to provide registered nurses updated educational and professional growth, salary increases, and the most recent evidence-based practice and research (Baucom, 2012). Reported outcomes of clinical career ladder revisions such as increased salary bonus and education benefits have been proven to improve program satisfaction (Korman \& Eliades, 2010). In this study, the main reason selected by participants as their perceived benefit towards participation in CCAP was monetary reward, followed by professional recognition, professional reward, and professional gratitude. Participants found that the application process was reasonable, and they were satisfied with the offered rewards and recognition. CCAP participants thought their areas benefited from their participation in CCAP and that meeting the top level of the ladder was achievable by stretching a little outside of their daily work responsibilities. Most participants indicated that they would continue to participate in the future.

\section{Perceived Barriers Towards Participation in PNAP and CCAP}

Even though clinical ladders exist in many facilities, one of the biggest challenges is to increase nurses' participation. Some of the barriers include the perception that the ladder documents a nurse's accomplishments but does not determine her proficiency (Knoche \& Meucci, 2015). Nurse anesthetists expressed the lack of time during working hours to pursue professional development activities and lack of manager engagement as barriers (Averlid, 2017). Additionally, clinical ladder programs are not always available in outpatient settings such as clinics (Tetuan, Browder, Ohm, Mosier 2013). Others expressed it took up too much time and energy and can become an obstacle towards personal responsibilities (Tetuan, Browder, Ohm, \& Mosier, 2013). Zehler et al. (2015) reported that the biggest barrier was committee attendance and the time it took away from patient care. In one study, staff surveyed indicated that one concern was the structure and function of the clinical ladder program (Winslow et al., 2011). In this study, the top perceived barrier for participation in the old clinical ladder (PNAP) selected by the participants was the research and evidence-based paperwork requirement. The participants thought that the PNAP criteria that were hardest to attain were the research projects, the appraisal of evidence-based practice, and the patient safety projects. In addition, the PNAP application process was considered time-consuming, and the paperwork associated with the application was overwhelming. The majority of nurses who did not participate in CCAP was because they did not qualify but indicated that they will more likely participate in CCAP in the future once they are eligible.

\section{General Attitude, Job Satisfaction, and Likelihood to Stay}

Although several studies addressed job satisfaction and retention of nurses participating in clinical ladder programs, a clear relationship between career ladder programs, job satisfaction, and retention has not been established (Korman 2010). However, multiple studies have positively linked clinical ladder programs to increased job satisfaction, retention, recruitment, and patient satisfaction (Watts, 2010). Ke and Hung 
(2017) found a significant difference in nurses' intent to stay based on the clinical ladder. Nurses at the highest level of advancement were more willing to stay as compared to nurses who did not advance. Career advancement programs such as clinical ladders have been shown to enhance professional development, improve staff relations, reward competency, and heighten nurses' motivation in their work (Watts, 2010). Benefits include gaining recognition with peers and administration, personal satisfaction, financial incentives, and personal growth (Tetuan, Browder, Ohm, \& Mosier, 2013; Watts, 2010). In this study, the CCAP and non-CCAP participants were compared regarding their job satisfaction and likelihood to stay in their jobs. The results showed that those who participated in CCAP indicated a higher level of satisfaction with their jobs than those who did not participate. In addition, those who participated in CCAP indicated they were more likely to stay in their jobs than those who did not participate. The participants' general attitude toward CCAP were measured and compared between the CCAP participants and those who did not participate. The findings indicated one major difference between the two groups where more CCAP participants believed that the use of the ladder demonstrates support of the direct care nurse. The respondents were also asked about the CCAP criteria that were the hardest to meet. The hardest criteria to meet on the CCAP was the years of service, floating, assuming the charge nurse role and being a member of entity project or committee.

In summary, the CCAP participants perceived money as the main reason for participation; that the CCAP application process is more reasonable than the PNAP application process and that they were happy and satisfied with the benefits and rewards the CCAP program has to offer to its applicants. The CCAP participants felt that CCAP benefited not only them but also their work areas as they have become advanced and expert nurses. They also realized that with the new CCAP program, the Expert level is more reachable and that they will continue to be participants in the future.

In the old career ladder program (PNAP), participants were reluctant or unable to participate due to the most difficult barrier, research. PNAP paperwork seemed to be overwhelming and time-consuming, resulting in low participation rates throughout the organization. The only reason nurses did not participate in CCAP was that they were ineligible. The nurses who participated in CCAP showed higher job satisfaction and more likelihood to stay in their jobs leading to the conclusion that the CCAP program is a great nurse retention program/tool.

The CCAP ladder showed support of the nursing administrators to the direct care nurses. However, the most difficult criteria to meet the CCAP included years of service, floating, assuming the charge nurse role, and being a member of an entity project or committee.
Therefore a revision and reevaluation of the criteria by the nursing leaders was needed.

\section{IMPLICATIONS FOR NURSING PRACTICE}

Nurse leaders are continuously challenged to retain quality nurses at the bedside. Clinical ladders are essential for improving nurse retention and reducing turnover rates. Clinical ladders can be useful in minimizing nurses' turnover and improving job satisfaction. Nurse leaders ought to understand the impact of clinical ladders on their workforce and continuously evaluate their effectiveness. In this setting, leaders quickly realized that in order to improve nurse participation rate is their clinical ladder (PNAP) thus improving nurse satisfaction, a change needed to occur. PNAP was revised and a new clinical ladder was introduced, CCAP.

After one year of its implementation, CCAP has been shown to improve staff satisfaction and likelihood to remain in the job. The feedback received from this research study was used to modify the current CCAP version. The changes made to the current CCAP application included adding points to formal nursing education. Therefore, incentive points will be awarded upon completion of the next educational level during the application period. This would assist in increasing the Bachelor of Science in Nursing (BSN) and Masters of Science in Nursing (MSN) degree holders hired. Furthermore, more points were granted to participants for their years of service at the institution thus rewarding and encouraging nurses' loyalty to the organization. The research section was reorganized and is now associated with more points to emphasize the importance of the research, even though it is not a mandatory requirement for advancement. The new CCAP version will be rolled out after educating all nurses and nurse leaders on the new application and criteria.

\section{CONCLUSION}

To increase participation of bedside nurses in clinical career ladders, nurse leaders should regularly review these career ladders to make modifications that are impactful on nurse retention and nurse job satisfaction by integrating appropriate satisfiers. The CCAP program replaced the PNAP program based on bedside nurses' feedback. After one year of the CCAP implementation, bedside nurses are pleased with the benefits this program has to offer and are more willing to stay at the bedside.

\section{ACKNOWLEDGEMENT}

The author wishes to thank and acknowledge Ruth Ohm, Ph.D., RN, Professor at Barker University School of Nursing for permission to share and modify 
The Professional Nurse Contribution Ladder Instrument (PNCL) for its use in conducting this study.

\section{DECLARATION OF INTEREST}

The authors report no conflicts of interest. The authors alone are responsible for the content and writing of the paper.

\section{AUTHORS}

Nada Wakim, PhD, RN, NE-BC, AVP of Nursing, South Miami Hospital, Miami, FL, US. Correspondence regarding this paper can be directed at NadaW@baptisthealth.net.

Nohemi Sadule-Rios, Ph.D., APRN, Nur se Scientist, Baptist Health South Florida, Miami, FL, US.

Suzanne Balbosa-Saunders, MSN, MSHA, RN, NEA- BC, Miami Cancer Institute, Miami, FL, US.

Eve Butler, PhD, RN, former Nurse Scientist, Baptist Health South Florida, Miami, FL, US.

Becky Montesino-King, DNP, RN, NEA-BC, CENP, Former Vice President/Chief Nursing Officer, Baptist Health South Florida, Miami, FL, US

\section{REFERENCES}

American Association of Colleges of Nursing (2014). Nursing Shortage Fact Sheet. Retrieved from http://www.aacn.nche.edu/media-relations/ fact-sheets/nursing-shortage

Averlid, G. (2017). Norwegian nurse anesthetist perceptions of professional development and

the influence of production pressure. American Association of Nurse Anesthetists, 85(5), 345-351.

Baucom, B. (2012). Nurse' Perception of Clinical Ladder Programs. Retrieved from Nursing Theses and Capstone Projects https://gigital commons.gardner-webb.edu/nursing_etd/99

Bureau of Labor Statistics (2013). Employment Pro jections: 2012-2022. Retrieved from http:// www.bls.gov/news.release/pdf/ecopro.pdf

Ke, Y. T. \& Hung, C. H. (2017). Predictors of nurses' intent to continue working at their current hospital. Nursing Economics, 35(5), 259266.

Knoche, E. \& Meucci, J. (2015). Competencies with in a professional clinical ladder. Journal for

Nurses in Professional Development, 31(2), 91-99.

Korman, C.\& Eliades, A. (2010). Evaluation through Research of a Three-Track Career Ladder
Program for Registered Nurses. Journal for Nurses in Staff Development, 26(6), 260-266

Hariyati, T. S., Igarashi, K, Fujinami, Y, Susilaning sih, F. S., \& Prayenti (2017). Correlation

between career ladder, continuing professional development, and nurse satisfaction: A case study in Indonesia. International Journal of Caring Sciences, 10(3), 1490-1497.

Pierson, M. A., Liggett, C., \& Moore, K. S. (2010). Twenty years of experience with a clinical

ladder: A tool for professional growth, evidence-based practice, recruitment, and retention. The Journal of Continuing Education in Nursing, 41(1), 33-40.

Riley, J., Rolband, D., Jamea, D., \& Norton, H. (2009). Clinical ladder. Nurses' perceptions and satisfiers. The Journal of Nursing Administration, 39(4), 182-188. doi: 10.1097/ NNA.0b013e31819c9cc0

Tetuan, T., Browder, B., Ohm, R, \& Mosier, M (2013). The Evaluation of a Professional Nurse Con tribution Ladder in an Integrated Health Care System. AAACN Viewpoint. American Academy of Ambulatory Care Nursing. Retrieved from https://www.high-beam.com/ doc/1P3-3069670871.html

Warman G., Williams F., Herrero A., Fazeli P., \& White-Williams C. (2016). The Design and redesign of a clinical ladder program. Journal of Nursing in Professional Development, (32) 6, E1-E7. DOI: 10.1097/NND.000000000000 0307

Watts, M. D. (2010). Certification and clinical ladder as the impetus for professional development. Critical Care Nurse Quarterly, 33(1), 52-59.

Winslow, S. Knight, D., Rosson, J., Fickley, S., Rich ards, K., \& Rumbley, N. (2011). Staff Nurses Revitalize a Clinical Ladder Program through Shared Governance. Journal for

Nurses in Staff Development, 27(1), 13-17.

Zehler J., Covert C., Seiler L., Lewis M, Perazzo J., \& Beery T. A. (2015). One rung at a time:

What affects clinical ladder participation? Nursing Management, 46(4), 30 - 37. 